\title{
The leadership practices of the dean of Combined Arms Academy
}

\author{
Matebe Tafere \\ Bahir Dar University, Ethiopia. \\ Received 9 January, 2014, Accepted 30 March, 2014
}

\begin{abstract}
This study is on the leadership practices of the dean of Combined Army Academy. The research is a qualitative design. The academic staff members were the participants of the study. Formal and informal conversational interview approaches, personal observation and document analysis were the instruments of the study. Thematic analysis was used for analyzing the data. Accordingly, the research findings revealed serious problems in the dean's leadership. That is, the dean's leadership practice was found to be loosely linked to each of the indicators employed in assessing his leadership effectiveness. Hence, it was suggested that the academy should revisit the academic leadership practices that had been exercised, and to genuinely see how much the academic leadership had been responsive to the group and institutional concerns if it is to grow and develop.
\end{abstract}

Key words: Leadership, academy, dean, defense.

\section{INTRODUCTION}

The study was conducted at Combined Army Academy, one of the recently established higher educational institutions in the Ministry of National Defense of Ethiopia. The Academy is situated at Awash Arba, the eastern part of Ethiopia, which is $250 \mathrm{~km}$ from Addis Ababa, the capital city of Ethiopia.

The Ethiopian Ministry of National Defense in its five year strategic plan has revealed that it will make concerted effort to strengthen the tank capacity of Ethiopia in terms of both hardware as well as qualified professional power. This in fact was done based on the belief that lifting the capacity of the tank units has become detrimental to increasing deterrent by dissuading military action by countries that otherwise might be inclined to attack the sovereignty of the country and interfere with its national interest.

The vast peripheral plain lowland area of Ethiopia has comparative advantage for the use of tank force than other means in case any danger emerges that threaten the interest and security of the country across the border areas. Deploying tank units in these areas can have much better return than conventional warfare dependent on massive deployment of personnel.

Currently, the Ethiopian army has some tank units and the commanders of the units have some limitations to lead their units to the standard that the task demands. Hence, opening Combined Army Academy has become eminent to upgrade the professional competency of the

E-mail: matebetafere@yahoo.com, matebietafere@yahoo.com.

Author a gree that this article rema in permanently open access under the terms of the Creative Commons Attribution Lic ense 4.0 Intemational Lic ense 
tank unit commanders so that they can discharge their responsibility effectively by using the knowledge and skill they got from training and education during their stay in the Academy.

Thus, from its background and its rational for establishment, we can understand that special focus has been given to the academy in building the capacity of the professional army that we have today. However, the establishment of the academy by itself does not guarantee the accomplishment of the missions assumed to be addressed at the end. Instead, it calls for the provision of organized and responsive leadership systems.

The leadership needs to be purposeful and intentional. On a more profound level, the leadership should be practiced in such a way as to be socially responsible. This kind of social responsibility is involved both in the outcomes and content of the groups' purpose, as well as in the group's process. Leadership effectiveness begins with self-awareness and self understanding and grows to an understanding of others (Harling, 1989). Moreover, leadership happens through relationship among people engaged. As a relational process, leadership requires the highest possible standards of credibility, authenticity, integrity, and ethical conduct. Ethical leaders model positive behaviors that influence the actions of others (Komives, 1998).

Leadership is a concern to all of us. As individuals and groups, we have a responsibility to contribute effectively as members of organization, local communities, nations, and in the world community (Bush, 1986). That is, organizational leadership effectiveness involves the participation of all involved in the process. Moreover, though leadership is our day-to-day practice, it demands to reflect core issues related to leading people. To lead others, primarily we need to be clear of where we are going? What is our vision? What are the critical success factors? How do we relate them to the realities of people? What are the basic situations that affect effectiveness etc? The answers to these questions are the concerns of leaders (Bennis and Townsend, 1995).

Komives (1998) emphasized the determinants of leadership effectiveness. Leadership effectiveness, according to this author, is defined as a process of influencing and getting result. To be influential, the leader needs to be able to build trust, which is the foundation for leadership effectiveness. A leader also is supposed to establish trust as a function of his/her leadership characteristics, the nature of the followers and the situation. That is, if these three variables interact successfully, the leader is likely to establish trust with his/her staff, which would help him/her to have followers. Once, he/she has created many followers among the group he/she is leading, influencing, sharing vision and thereby having objectives met easily. Though leadership is a function of leaders' characteristics, the nature of followers and the situation, most scholars (Waters et al., 2003) argue that the leaders' characteristics take the lion's share in shaping the followers and the situation. That is, leadership effectiveness, among other things, highly rests on the leaders' characteristics. Personal characteristics of the leaders as determinants of leadership effectiveness encompass a range of variables associated with the knowledge, skill and attitude of the leader. In this regard, different authors proposed as many personal characteristics as possible. Some even went on by stating detailed personal traits, some of which seem difficult to measure. In any case, those proposed by Komives (1998) seemed comprehensive, and in fact were also shared by others like Waters et al. (2003). Hence, Komives (1998) proposed the following core characteristics as determinants of leadership effectiveness: integrity (honesty), demonstrated commitment for service orientation, consistency (dependability, predictability), communication ( $r / p$ skills), expertise ( for both strategic and operational leadership), ethical orientation, emotional maturity, authority to reward or punish, objectivity and straightforwardness, charisma (grace), vision, open mindedness and flexibility, accessibility, empowerment, courage and confidence, inspiration, understanding people, assertiveness, recognition and respect, decisiveness and positive personality.

Similarly, acknowledging that there are multidimensional factors for leadership effectiveness, Waters et al. (2003) also focused on discussing the following as prevailing considerations: personal characteristics, situational characteristics (leader-member relations, task structure, position power), motivational mechanisms and decision making practices. Personal characteristics of a leader in this case refer to personal attributes related to the leader like the ones proposed by Komives (1998). Leadermember relations could also cover aspects such as the relationship between the leader and the staff or followers. The task structure, on the other hand, refers to aspects such as the clarity of expectations, objectives, tasks, duties, responsibilities etc. The position power, as one determinant of leadership effectiveness, also refers to the effective and efficient exercise of authority vested in ones leadership. Besides, motivational mechanisms are also believed to make a difference in leadership effectiveness; and it may refer to application of a range of mechanisms for encouraging, inspiring, rewarding etc of the staff. Moreover, the decision making practices of leaders is a critical factor in determining their successes or failures. Decision making as part of the leadership characteristics could cover aspects such as the leaders' ability in making timely, participatory and shared decisions.

Reminding readers that there are different models or approaches for addressing leadership effectiveness, Komives, in this regard, reflected that there are strong empirical evidences for suggesting those core determinants of leadership effectiveness, and he also noted that his evidences had been collected through studies conducted on higher education academic leadership, which in fact corresponds with the purpose of this study. 
Hence, it would seem sound to use Komives' conceptual framework while measuring leadership effectiveness.

Provision of responsive leadership practice or services for the academy as a higher educational institution, therefore, involves the commitment and orientation of the different stakeholders in the academy, among whom is the dean, who is assumed to pave the way for the desired promotion of the academy. Taking the active role of the dean in promoting the Academy into consideration, the study was channeled to focus on examining the leadership practices of the dean using the above conceptual framework. So, this study is assumed to play a great role in adding some inputs to the efforts employed in ensuring the production of competent mechanized unit commanders which is assumed to be effected through sound and responsive academic leadership at the academy under study.

\section{METHODOLOGY}

The main purpose of this study is to examine the academic leadership practices of the Combined Army Academy's Dean. Thus, this section describes the methodological elements of the study including design of the study, research participants, and instruments for data gathering, procedures of data gathering and ethical considerations, as well as the data analysis techniques employed. The justifications for using the specific methods are also given.

\section{Design of the study}

Qualitative methods were preferred and employed to enhance, validate and add depth to the data collected. As Wiersma (1995) noted, qualitative designs are less structured than quantitative ones; and in qualitative design, the specific procedures are identified during the research rather than ahead of time. So, qualitative methods were employed in this study for the in-depth description of the data collected, and more importantly, helped the researcher to flexibly collect and analyze data reflecting the perspectives of the academic staff members of the academy under study.

\section{Participants}

As it was mentioned earlier, there were ten professionals in the academy with similar academic background. The study participants, composed of two civilians and two military personnel, were selected purposefully, taking their seniority and management experience into consideration. All the respondents had also similar years of work experiences in the academy in addition to their desired educational background. So, they were expected to provide meaningful information on the leadership practices of the dean under study. To this end, they were informed about the purpose of the study and what is expected of them. Fortunately, all were very much interested in taking part in the interview, and hence, they willingly gave information related to the topic under focus.

\section{Instruments}

In this study, qualitative data collection techniques were used, of which interview took the largest coverage. The interview method of collecting data involves presentation of oral-verbal stimuli and reply in terms of oral-verbal responses. This method can be used through personal interviews and, if possible, through telephone interviews.

\section{Procedures of data collection}

The researcher, having the purpose of the study in mind, went to Combined Army Academy. Then, he tried to have the full lists of the academic staff members and found out that there were no significant disparities among the staff members in terms of sex, age, academic background, and work experiences. This helped the researcher to take representative respondents, and these respondents or study participants were selected using purposive sampling technique; the sampling technique employed helped the researcher in identifying respondents who had rich and related information on the study under focus. Right after selecting the respondents, what the researcher did was orienting those respondents about the purpose of the study and its possible relevance. Fortunately, the respondents all together were interested in the interview, and then the researcher started interviewing with the time frame set for each of the respondents.

A battery operated tape recorder was used during the interview. Apart from the tape recordings, personal observations were taken as field notes so as to make the data more reliable. After the end of the data gathering process, all the recorded interviews and field notes were transcribed and given to respondents to assure them that the information was taken by the researchers as it was clearly reported by the respondents. The respondents saw it and confirmed that it was the actual information on what had been happening as it was reported by them.

Apart from the personal observations conducted, the researcher wanted to ensure the validity and reliability of the data collected, and hence, asked for evidences of official documents. Fortunately, he had a chance to see petition of the academic staff members against the dean Which was reported to the higher officials of the institution. That petition document was a direct reflection of the data collected from interview and personal observation. This helped the researcher to be sure on the validity and reliability of the data, and to proceed to the next stages of the study. After having collected, the raw data were transcribed, coded, and categories were made. From the 
categories made, patterns were also formulated based on the themes originated from the categories so as to make the data ready for analysis. The analysis was made in line with the categories or patterns formed. Based on the analysis conducted, interpretations of data

were also undertaken to come up with the necessary findings. Finally, based on the findings obtained, conclusions were drawn, and reflections were forwarded accordingly.

\section{DATA ANALYSIS}

\section{Data analysis based on interviews}

Personal interview method requires the interviewer asking the other person or persons questions generally in a face-to-face contact. At times, the interviewee may also ask certain questions and the interviewer responds to these, but usually the interviewer initiates the interview and collects the information.

This sort of interview may be in the form of direct personal investigation or it may be indirect oral investigation. In the case of direct personal investigation, the interviewer has to collect the information personally from the sources concerned. He has to be on the spot and has to meet people from whom data have to be collected. This method is particularly suitable for intensive investigations. Accordingly, formal and an informal conversational interview approaches were used by the researcher while gathering the data.

The informal conversational approach in particular helped much in making the data gathering process more responsive to the perspectives of individual respondents. That is, issues related to the personal or emotional characteristics of the dean as an academic leader, the motivational mechanisms employed by the dean in reinforcing the academic staff members, the extent of the situational characteristics in either promoting or affecting the dean's leadership practice, the decision making practices that had been employed or exercised by the dean, and the actions or measures that had been taken by the academic professionals in response to the leadership practices of the dean were raised during the interview, and all the issues were addressed by the respondents adequately.

To this end, the response sets were found to be by far relevant to the purpose of the study and in addressing the particular issues that need to be raised with leadership practices in general.

\section{Data analysis based on documents}

In addition to the data collected through interview, attempts were made to undertake document analysis. In this case, the major intention was to examine or look into the minutes of decisions held at different times, the participants involved in those decisions, the nature of decisions and actions taken by the dean for successes or failures. Evidences or documents notifying the actions of the staff against or pro the dean's subsequent actions were also examined.

\section{Data analysis based on observation}

Another important instrument employed while collecting the research data was observation. Observation as a tool of research requires systematic and careful examination of the phenomena being studied; and specifically, researchers who choose to use observation must conduct their observations in a way that results in accurate, unbiased, and richly detailed information (Wiersma, 2009). Under the observation method, the information is sought by way of investigator's own direct observation without asking from the respondent. The information obtained under this method relates to what is currently happening; it is not complicated by either the past behaviour or future intentions or attitudes. Besides, this method is independent of respondents' willingness to respond and as such is relatively less demanding of active cooperation on the part of respondents as it happens in the interview or the questionnaire method (Kothari, 2004). Hence, the researcher spent about ten days for undertaking actual observation of what the staff was feeling about the dean's leadership. The researcher spent the whole day with the staff, slept with staff, ate with the staff in all of those ten days. His stay with the staff in the academy in fact helped him to have a detailed and reliable description of what was interviewed, for it was supported with the researcher's personnel observation and supportive official documents confirming the validity and reliability of the interview data.

\section{DISCUSSION}

This is a section where the data are presented and discussed in an organized pattern, which is formed based on the possible themes emanated from the raw data. Accordingly, the following five themes have been drawn from the raw data: personal characteristics of the dean, motivational mechanisms employed in his leadership practices, situational factors associated in his leadership (leader-member relations, position power, and the task structure), decision making practices and the communication system in practice, and the actions taken by the staff members.

Hence, the relative descriptions of the leadership practices in line with the themes (patterns) formulated for data presentation and discussion are given in the following sections.

\section{Personal characteristics of the dean}

The dean under study had his second degree in 
curriculum and teacher education about fifteen years ago. He joined the academy a year ago, and he had been working in different government and non government organizations before he joined the academy under study. In the interviews conducted, different interviewees had tried to point out some common personal characteristics of the dean. Personal characteristics, as indicated by George and Jones (2005), include: task relevant knowledge, which ensures that leaders know what should be done, how should it be done, and what resources are required for a group and organization to achieve its goals; dominance, an individual need to exert influence and control over other to achieve organizational goals; self confidence, which helps leader influence followers and motivate them to pursue in the face of obstacles or difficulties; energy/activity levels which, when high, helps a leader deal with the many demands he or she faces in a day to day basis; integrity and honesty, which ensures that a leader behaves ethically and is worthy of his or her followers' trust and confidence; emotional maturity, which ensures that a leader is not overly self-centered, can control his or her feelings, and can accept criticism; and intelligence, which helps a leader solve complex problems.

Hence, the categories of description with personal characteristics have been made to be in line with the above issues. Accordingly, interviewee " $A$ " said that "I think the dean must have some psychological problems". $\mathrm{He}$ also continued saying that "the dean does not know what to do, and we don't know too." In expressing his energy or activity levels with managing the many demands he face on day-to-day basis, the interviewee said that " he usually complains on everything that happened to him in the academy". With the efforts geared towards influencing or channeling the staff members, the interviewee also said that " he tries to act as a boss and wants the staff members to develop fear towards him". The interviewee also associated the dean's bossy feeling with confidence issues by saying ".. he is not confident to convince the staff members on what to do and how to do it". Moreover, the interviewee, referring to the dean's intelligence in solving problems said, "he asked release two times within four months duration, and gave a written warning for three staff members and even got quarreled with almost all staff members within not more than five months since he got employed".

Interviewee "B", on his turn, also tried to pose some points which are related to the personal characteristics of the dean. Accordingly, he said, "we have been going haphazardly and we do not know where to stop our journey", and he associated the blame to the dean's acts. In supporting the blame, he said, "...the dean himself does not have an organized emotional adjustment. He fails to understand how he should behave, and tends to act like children by complaining about everything that happens to him. He usually tends to consider himself as the only matured person who knows everything, and hence, he doesn't want to listen to any comments from others." The interviewee, in describing the dean's emotional maturity, also went on to say, "what worries him is not the institutional performance rather his being accepted as a boss having control over everything." Besides, with respect to the dean's institutional concerns, the interviewee further noted that "as far as I am concerned, I do not dare to say that we have been working for the institution, rather we have been defending ourselves from the dean's attack." He also tried to associate the blame of this concern to the dean's self-centered perspectives as already quoted above.

Interviewee " $C$ " in describing the personal characteristics of the dean, also tried to point out some issues in a consolidated manner. Accordingly, he said that "...our dean is very autocratic and with no reasonable selfconfidence; immature or gets upset for everything that happens to him; dishonest-reporting everything to the top officials, some fabricated and others exaggerated; he is the one who usually worries for sustaining his power but not for institutional merit." In describing the dean's practices, in influencing the followers by having a meritorious vision and communicating it to the followers, the interviewees said that "we do not have the institutional vision, mission and goals, and hence, what we have been doing was simply doing what is right for him and defending ourselves from attack".

The last interviewee "D" was very eager to be interviewed, and raised so many details about the personal characteristics of the dean under focus. Accordingly, he said:

He has been assassinating the characters of all staff members; he frequently gave written warnings, and threatening has become common to all; he is not ready to listen to comments and when someone tells him his weakness, he prepares himself for revenge; and he usually spends his time in fabricating imaginary happenings that can create gaps between staff members and students, between staff members and higher officials, and among staff members

Further, in describing his charismatic character, the interview also said that " he is too ambitious but unfit for administrative positions because he does not know even how to act and seem as an administrative body of an institution".

One important point in the practice of leadership is identifying those personal characteristics of a leader that help individuals, group, and organizations achieve their multiple goals (George and Jones, 2005). Accordingly, attempts were made to identify the personal characteristics of the dean, as an academic leader.

Unfortunately, all the interviewees characterized the dean as an academic leader who: lacks the necessary intelligence in dealing with problems or inconveniences; lacks task relevant knowledge to set or establish a transparent system which clearly indicates the duties, responsibilities and accountabilities of the academic staff 
members; is very autocratic and ambitious for having control over everything irrespective of his weakness; lacks the necessary self confidence in sharing power among the academic staff members; lacks the energy level or tolerance for handling day-to-day irregularities; drives out trust and integrity in the institution; and does not have the necessary emotional maturity to plan and work for the institutional merit.

The data obtained through document analysis and observation also confirmed that the dean wrote a warning letter to most of the staff members, and every academic staff member there seemed to get worried about it. The staff members seemed to feel that one cannot predict as to why and how the dean decides to give warnings. His personal feeling, in this case, seemed to dominate the atmosphere. Hence, from the above description one can understand that the dean had not been exercising his authorities for institutional merits and no inputs seemed to have been added to the institution in the presence of the dean. Instead, it would be possible to say that had he not been there, the institution would have gone one step forward. Besides, it would also be possible to say that unless the dean makes dramatic changes in his leadership characteristics or unless he is replaced, the institution is likely to fall into big crisis not only in failing to achieve its objectives but also in losing the majority of its productive work forces.

\section{Motivational mechanisms employed}

In this section, the motivational mechanisms being employed by the dean in his leadership practices have been raised, and the interviewees all together confirmed as there was no any effort to motivate the staff members. According to the perspectives of the academic staff, the dean has rather been employing demotivating mechanisms which were contrary to the institutional objectives. The detail description can be seen as it is presented and discussed in the following paragraph.

Interviewee "A", for example, said, "... what he is doing is simply creating problems and obstacles which demotivate the academic staff members from working hard." Interviewee" B" on his part also said, "...the dean must have some hidden agenda apart from the vision of the academy. Had it not been for that case, he would not have been creating confusion and discouragements with almost all academic staff members." Moreover, interviewee "C" added that "he does not have any good relationship with any of his subordinates because his daily activities are discouraging and upsetting for the academic staff members." Interviewee "D" further descrybed the dean's motivational mechanisms as, "he contrarily revenges those academic staff members who tend to perform high".

It was also clearly described by the interviewees that no motivational mechanisms had been designed, and even no efforts had been made to encourage the academic staff members. Rather, all the efforts taken were geared to discourage the efforts of the academic staff members.

The accomplishment of the institutional objectives heavily lies on the motivation and commitment of its workforces. The motivation and commitment of the workforces are also likely to be strengthened when a leader positively reinforces subordinates' desirable behaviors. Leaders who notice when their followers do a good job and acknowledge with accomplishments of whatever form are likely to succeed in achieving institutional objectives (Bush, 1986).

In contrast to the above arguments, the Dean of the Combined Army Academy had not been employing any motivational mechanisms. Rather, all what he had been doing seemed a deliberate attempt to discourage the work forces of the institution stated. Perhaps, the need to motivate or reinforce the workforce emanates from the institutional perspectives of the leader. However, as was already indicated earlier, the dean's priorities seemed to focus on ensuring personal gratification by having control over everything irrespective of institutional concerns. So, when one's exaggerated prior concern for self gratification fails, it is more likely that he or she would act against the interest of others and thereby the interest of the institution (Murgatroyd and Gray, 1984), and hence, it was all what happened to the dean and what he had been doing in that institution.

\section{Situational characteristics associated to his leadership}

In this section, the information related to the situational characteristics associated to the dean's leadership practices is presented and discussed. Situational characteristics in this case would mean the extent to which the situation allows the leader to easily guide and channel subordinate behavior in the direction of high performance and goal attainment. When a situation is favorable for leading, it is easier for a leader to exert influence than it is when situation is unfavorable. As is indicated by Thomson (1993) and George and Jones (2005), situational characteristics are made to include three elements: leadermember relations, position power, and task structure. Accordingly, the collected data or results are presented in line with these three elements, and the corresponding discussion is made as can be seen in the following subsections.

\section{Leader-member relations}

The interviewees, all together, confirmed that the leadermember relation was not encouraging. The dean had not been working towards building positive relationship 
between the staff members and him as an academic leader. To understand the interviewee's individual perspectives, we can have a look at their respective quotations as they are presented below.

Interviewee "A" said, "...the dean does not communicate with, I can say, almost all the academic staff members and even with the cafeteria workers". Interviewee "B", on his part, also said, "we have really been in a poisoned environment" and tried to throw the blame to dean's activities. Interviewee " $\mathrm{C}$ " also added in indicating as the dean was not communicating with them and said, "... no one was willing to give his ears to us." Adding emphasis, interviewee "D" noted, "violations of the academic members' rights has become a common event; and the dean usually spends his time in fabricating imaginary happening that can create gaps between staff members and students, between academic staff members and administrative staff members, and among academic staff members." Thus, all these quotations tell us that there was no healthy relationship between the academic staff members and the dean, as an academic leader.

Besides, the observation results confirmed that there was no smooth communication between the dean and the staff members. In this regard, it would be wise to mention the living style of the staff in general. Because the academy was a military institution built far from the local population, all the staff members including the dean were living inside the academy, in a building reserved for such purposes. Accordingly, all the staff members were required to share the same cafeteria, TV room, staff lounge, and other services. Other things being constant, this way of living is supposed to increase interaction among the staff, without which life would really be difficult. Contrarily, as the researcher was able to observe in his ten days stay in the academy, the dean was not communicating with the staff in each of the service areas mentioned earlier, and he even surprisingly was unable to have smooth communications with the cafeteria workers. This can be referred to as a manifestation of social disability, without which leadership would be a futile exercise.

When there is healthy relationship between the leader and followers, the situation is favorable for leading. Likewise, when the leader-member relations are poor, followers dislike or distrust their leader, and the situation is unfavorable for leading (Robbins, 2005). Accordingly, attempts were made to see the leader-member relations of the institution under study. The result shows that the leader-member relation was very much poor, even worse. In fact, the blame went to the dean's poor personal characteristics because relationship is highly dependent on one's personal characteristics. That is, the inappropriate use of his power in influencing the staff members, his lack of emotional maturity in handing day-to-day confrontation, his lack of the necessary intelligence in dealing with complex issues had resulted in the development of unhealthy relationships between the academic staff members and the dean. So, it would be important to note that the dean lost one key element of leaders that is the human relation skill, and without which leadership effectiveness is unthinkable (Komives, 1989).

\section{The position power}

In any organizational setting, the position power given to the leader is likely to determine his effectiveness in influencing the followers towards the achievement of a common goal or organizational objectives. Accordingly, the extent of the formal position power given for the dean in influencing the followers is presented as follows.

When interviewee "A" was asked whether they have been informing the inconveniences with leadership practices to the academy's commandant, he felt a bit annoyed and said, "in fact, we tried to report the matter, but the commandant himself didn't want to give his ears to us for he has already given an absolute power to the dean to do what he feels is right". Interviewee " $\mathrm{B}$ " on his part also said, "what surprised us was the perspectives of the academy's military commandants in that they have already set a mental framework that the dean is the only person responsible. For this reason, they gave him a power to do everything." Moreover, interviewee "C" said, "... what we have been doing was simply doing what is right for the dean because he was authorized to take actions on everybody." Adding emphasis, interviewee "D" also noted, "irrespective of all his evils, the top officials have given him the power to influence the academic staff members in a way he likes."

Attempts, as already indicated in the result section, were made to see the favorability of the situation for the dean in line with those three elements. Position, for example, is the amount of formal authority that a leader has (Grint, 2000). Likewise, all the interviewees confirmed that the dean had been given a strong power to have control over every decision in the situation. However, he was not using his power for channeling the staff members to achieve the desired institutional goals. Instead, he used his power to impose the academic staff with the interest to gratify his bossy feelings. That is, he was using his power as a means for threatening the academic staff members so as to get due respect and recognition irrespective of his personal qualities. As seen from the documents attached in the human resource section of the academy, the dean was frequently giving written warnings to most of his staff. The staff members also reflected in their interview that the dean was not asked or challenged by his leaders as to why he was writing those warning letters so frequently.

In this regard, he seemed to forget the principle that power operates under the same logic as love: the more he gives to others the more he receives in return. That is, leaders can maximize their own power and their own opportunities for success by enabling the employees they 
supervise also to achieve their own sense of power and success. In very clear terms, if you are successful in giving your power to your followers, they will surely lift you on their shoulders to heights of power and success you never dreamed possible (Lunenburg and Ornstein, 1991). Hence, especially in an intellectual environment, the dean's forceful manipulation and threatening would not have a place. Intellectuals would like to question things they encounter, and hence, they are not suitable to get manipulated, and consequently, his leadership practices had fallen into crisis.

\section{The task structure}

Task structure is the extent to which the work to be performed by a group is clearly defined. The situations to which the activities of the group are organized to some extent help us to know the effectiveness of the dean's leadership. To be more specific, the leader from the outset is expected to set a common objective or vision that addresses the mission for which the institution is established. Following this, the leader has to make sure that the objective or vision set so far has been articulated by his staff members. Once he makes sure that the vision has been shared, he may have to create an affective task organization where everybody is clear about what is expected of him or her in achieving the vision. Then, after doing all these, the leaders' basic role would be facilitation, coordination, motivation, and monitoring and follow up (Komives, 1998). Accordingly, the perspectives of the interviewees regarding the task structure issues are presented and discussed as follows:

Interview "A" indicated, "he does not want to communicate the plans, visions and activities of the academy with the academic staff members". Interviewee "B" on his part also said that "in our academy, issues related to planning, reporting, job description, accountability, and motivation are not clear; we have been working haphazardly and we don't know where to stop our journey." Moreover, interviewee "C" indicated, "...almost all of the staff members have not been informed about the vision, objectives, plans and activities of the institutions." Interviewee "D" further said, "whatever smart or poor the staff members may be, they are all the same to the institution for there is no organized system which clearly indicates the duties, responsibilities, accountabilities, and authorities of the academic staff members in that institution."

In this regard, from what the interviewees said, it seemed evident that, the dean, as an academic leader, had not been exercising his leadership practices by communicating with the academic staff members on issues related to responsibilities, accountabilities and power structure. The lack of a clearly set task structure is an important component that affects the effectiveness of one's leadership practices. Task structure, when conceptualized, is the extent to which the work to be performed by a group is clearly defined. When a group has a specific goal that needs to be accomplished and when every group member knows how to go about achieving the goals, task structure is high. When group goals are vague or uncertain and members are not sure on how to go about performing their jobs, task structure is low. Situations are more favorable for leading when task structure is high (George and Jones, 2005).

In contrast, as was already described in the result section, the academic staff members were not informed about what and how to do, and even where to stop. Communication about the vision, and goals of the institution had not been made. Issues related to job description, responsibility, accountability etc... were not taken into account. Instead, all the activities had been performed haphazardly.

The leader is the one who sets common vision, communicate that vision to those concerned and paves the way for achieving that vision. However, the dean had not been aware about not only how to lead but also how to be led, because there is an argument that a good follower is more likely to be a good leader (Waters et al., 2003). So, it would be difficult to say that there was an academic leader in that institution

\section{Decision making practices}

Allowing subordinates to participate in decision-making and problem solving can enhance leadership. Participation helps to ensure that subordinates will accept a decision that affects them or requires support. Accordingly, the academic staff members' perspectives on the dean's decision-making practices are presented and discussed as in the following.

Interviewee "A" said that "all the decisions have been made by him, and have been communicated to us through announcements posted on the notice board." Interviewee "B" on his part also said that "... what we have been forced to do was simply doing what we are told to do without asking how and why questions, and waiting to see the ultimate result." Adding emphasis, interviewee " $C$ " indicated that "all the institutional decisions have been monopolized by the dean." Similarly, interviewee "D" also noted, "the dean, in any ways, does not want to share his decision-making powers."

Furthermore, it has clearly been reported by all the interviewees that almost all the institutional decisions were made by the dean alone, and all the academic staff members had no chances of participation rather than accepting the decisions made. That is, the necessary communication of the issues to be decided had not been made in that institution as can be seen from the respective quotations.

Allowing subordinates to participate in decision making and problem-solving can enhance leadership. 
Participation helps to ensure that subordinates will accept a decision that affects them or requires their support. Participation may also result in better decision if, for example, subordinates have information pertaining to the decision that the leader does not have. Additionally, participation can help foster subordinates' growth and development and may result in higher performance levels and job satisfaction (Adams, 1986).

The observation result also confirmed the decision making practices of the dean under focus; it was reported that almost all the decision had been made by the dean alone, and the decisions had been communicated to the staff members through the notice board. The dean was the sole source of direction for the tasks expected to be accomplished. The staff members were by far frustrated with the context of the working environment, and simply wait for directions to come from the dean. That is, the academic staff members had no say on deciding issues even related to their duties and responsibilities. This ultimately resulted in creating dissatisfaction and resistance with staff members, and the dean's leadership was challenged with group confrontation.

In this regard, it has been well researched and documented over the years that shared leadership makes a difference in organizational performances, and it has highly been recommended to be practiced in academic institutions where professionalism and academic autonomy dominates the atmosphere (Waters et al., 2003). However, in such situations where the staff lacks commitment and courage, and in a situation where the staff lacks meaningful participation and institutional ownership, failure may be a likely event for the institution. Today, more than before, allowing subordinates to participate in decision-making has become an important issue. To this effect, organizations are organizing their employees into self managed work teams with decision-making authority. So, the dean under study must have been the one who had been dominated with classical orientation, and if his trend continues, the institution will ultimately fall into big crisis.

\section{Actions taken by the academic staff members}

The actions taken by the subordinates either to support or to comment the leader can have a meritorious contribution in channeling the styles of leaders. Accordingly, the actions taken by the academic staff member towards the dean's leadership practices have been assessed, and the details are presented and discussed as follows.

Interviewee "A", for example, said, "...what we have decided to do was simply getting organized and challenging him whatever obstacles he tends to create, and the teaching and learning process of the academy has been made to become our second priority." Interviewee"B" added, "in fact, we are getting organized, and challenging him in different means". Interviewee " $\mathrm{C}$ " on his part also said, "ultimately, we have been becoming successful in getting organized in assuring leadership void so as not to be attacked." Moreover, interviewee "D" said, "we are trying to challenge him through different ways like faceto-face confrontations in groups and with written group reports to the higher educational institutions' coordinating office, which is established in Addis Ababa."

The interview result, then, seems to indicate that the academic staff members have started to challenge the dean in different ways. Besides, the document analysis, as it can be seen from the staff members' petition report, conducted shows that the academic staff members are challenging the dean in a very organized manner.

The ultimate goal of education is reasoning, which is likely to be developed through having necessary behavioral changes. Reasoning involves providing justifications for happenings. To this effect, intellectuals or academic professionals are expected to reason out the things they do though in relative sense. They are also expected to question the things they are confronted with (Komives, 1989). Accordingly, efforts were made to see how far the academic staff members in the context of the study challenge or question the action or decision of the dean as an academic leader.

As already indicated earlier, the dean was very autocratic in enforcing his monopolized decision on the staff members, who were not allowed to take part in the decision making process. Fortunately, as the document analysis result revealed, the staff members were more organized in challenging the dean, and they had even gone one step forward in reporting the matter to higher educational institutions coordination office, which is in Addis Ababa. This action seems to reflect a true quality of professionals, who are supposed to bring change. This is the culture that we have to cultivate especially in developing countries otherwise our overall fate would fall into the hands of some ill prepared leaders who seek to gratify their self interest irrespective of the biggest responsibilities they are supposed to hold. So, it would be possible to argue that the academic staff members in that institution, though late, had been exercising one of their responsibilities in bringing their leader to the right track, where group or institutional interest is reflected.

\section{CONCLUSION AND REFLECTIONS}

In the discussions made, the following major findings were obtained: the personal characteristics of the dean requires immediate adjustments if he is to continue with that leadership career; the situational factors were not favorable for the dean to lead, and in fact, he was accountable for making the situation unfavorable; no motivational mechanisms were designed and employed to reinforce the workforce; decision making efforts were made to rely on only one person, the dean; and it was also found out that the academic staff members had 
recently been getting organized in challenging the inappropriate action of the dean.

It would then be possible to conclude that the dean of that academy lacks the necessary leadership orientations, without which leadership is really difficult, and it seemed that even the Academy's Higher Commandants lack the necessary orientation of what academic leadership is. Had it not been for their lack of the necessary orientation of academic leadership, the Commandants of the Academy would not have given an absolute power for the dean to act in a way he likes irrespective of the group and institutional demands.

Academic leaders are expected to influence their followers by intellectually stimulating them to become aware of problems in their groups and organization, and view these problems from new perspective-one consistent with the leader's vision. They are expected to cause followers to view problems differently and feel some degree of responsibility for helping to solve them. Generally, a desired academic leadership seems to occur as the leader: increases followers' awareness of the importance of their tasks and the importance of performing them well; makes subordinates aware of their needs for personal growth, development, and accomplishment; and motivates their subordinates to work for the good of the organization rather than exclusively for their personal gain or benefit. Hence, it seems sound for the academy to revise the academic leadership practices that had been exercised, and to genuinely see how far the academic leadership had been responsive to the group and institutional interests.

\section{Conflict of Interests}

The author have not declared any conflict of interests.

\section{REFERENCES}

Adams JD (1986). Transforming Leadership: From Vision to Results. Virginia: Miles River Press

Bush T(1986). Theories of Educational Management. London: Paul Chapman

Bennis W, Townsend R (1995). Reinventing leadership: Strategies to Empower the Organization. http://www.publishersweekly.com/978-0688-12670-4
George JM, Jones GR (2005). Understanding and Managing Organizational Behavior. New Jersey: Pearson Education Inc.

Grint K (2000). The Arts of Leadership. Oxford: Oxford university press.

Harling P (1989). The Organizational Framework for Educational Leadership in Bus, T.(ed) Managing Education: Theory and Practices. Milton Keynes: Open University press

Komives RS (1998). Exploring Leadership for College Students who want to make a Difference. Jossey Bass: A Wiley Company Inc.

Lunenburg FC, Ornstein AC (1991). Educational Administration: Concepts and Practices. Wadsworth Publishing Company http://books.google.com.ng/books/about/Educational Administration. html?id=ynuiQgAACAAJ\&redir_esc=y

Murgatroyd S, Gray HL (1984). Leadership and the Effective School in Hurling $P$ (ed) New Directions in Educational Leadership. London: Falmer press.

Robbins SP (2005). Organizational Behavior: New Directions in Educational Leadership. London: Falmer press.

Robbins SP (2005). Organizational Behavior(11 ${ }^{\text {th }}$ ed). New jersey: Pearson Education Inc.

Thomson SD (1993). Principles for our changing Schools: The Knowledge and skill Base. Fairfax, VA: National Policy Board for Educational Administration.

Waters JT, Marzano RJ, McNulty BA (2003). Balanced Leadership: What 30 years of research tells us about the effect of leadership on student achievement. Aurora,Co: Mid-continent Research for Education and Learning.

Wiersma W (1995). Research methods in education: An Introduction. $6^{\text {th }}$ ed. Boston: Allyn and Bacon, Inc.

Wiersma W (2009). Research Methods in Education: An Introduction. New York: Pearson Education Inc. 